Article

\title{
Evaluation of Controlled Ovarian Stimulation Protocols in Patients with Normal and Low Ovarian Reserve: Analyses of miRNAs and Selected Target Genes Involved in the Proliferation of Human Cumulus Cells and Oocyte Quality
}

\author{
Giulia Russo ${ }^{1,+}$, Valentina Notarstefano ${ }^{1,+}{ }^{\oplus}$, Nina Montik ${ }^{2}$, Giorgia Gioacchini ${ }^{1}$, Elisabetta Giorgini ${ }^{1}{ }^{1}$, \\ Anna Rita Polidori ${ }^{2}$, Fulvia Antonia Candela ${ }^{2}$, Andrea Ciavattini ${ }^{2}$, Maurizio Cignitti ${ }^{2}$ and Oliana Carnevali ${ }^{1, *}$ (D \\ 1 Department of Life and Environmental Sciences, Università Politecnica delle Marche, Via Brecce Bianche, \\ 60131 Ancona, Italy; giu-rus@hotmail.com (G.R.); v.notarstefano@staff.univpm.it (V.N.); \\ giorgia.gioacchni@staff.univpm.it (G.G.); e.giorgini@staff.univpm.it (E.G.) \\ 2 Clinica Ostetrica Ginecologica, Università Politecnica delle Marche, Ospedale G. Salesi, Via F. Corridoni 11, \\ 60131 Ancona, Italy; nina.montik@ospedaliriuniti.marche.it (N.M.); \\ annarita.polidori@ospedaliriuniti.marche.it (A.R.P.); fulviaantonia.candela@ospedaliriuniti.marche.it (F.A.C.); \\ andrea.ciavattini@staff.univpm.it (A.C.); maurizio.cignitti@ospedaliriuniti.marche.it (M.C.) \\ check for \\ * Correspondence: o.carnevali@staff.univpm.it; Tel.: +39-071-2204940 \\ + These authors contributed equally to this work.
}

updates

Citation: Russo, G.; Notarstefano, V.; Montik, N.; Gioacchini, G.; Giorgini, E.; Polidori, A.R.; Candela, F.A.; Ciavattini, A.; Cignitti, M.; Carnevali, O. Evaluation of Controlled Ovarian Stimulation Protocols in Patients with Normal and Low Ovarian Reserve: Analyses of miRNAs and Selected Target Genes Involved in the Proliferation of Human Cumulus Cells and Oocyte Quality. Int. J. Mol. Sci. 2022, 23, 1713. https://doi.org/ $10.3390 /$ ijms 23031713

Academic Editors:

Vladimir Isachenko and Pilar Coy

Received: 8 November 202

Accepted: 30 January 2022

Published: 2 February 2022

Publisher's Note: MDPI stays neutral with regard to jurisdictional claims in published maps and institutional affiliations.

Copyright: (C) 2022 by the authors. Licensee MDPI, Basel, Switzerland. This article is an open access article distributed under the terms and conditions of the Creative Commons Attribution (CC BY) license (https:// creativecommons.org/licenses/by/ $4.0 /)$
Abstract: The oocyte and the surrounding cumulus cells (CCs) are deeply linked by a complex bidirectional cross-talk. In this light, the molecular analysis of the CCs is nowadays considered to be precious in providing information on oocyte quality. It is now clear that miRNAs play a key role in several ovarian functions, such as folliculogenesis, steroidogenesis, and ovulation. Thus, in this study, specific miRNAs, together with their target genes, were selected and investigated in CCs to assess the response of patients with normal (NR) and low (LR) ovarian reserve to two different controlled ovarian stimulation (COS) protocols, based on rFSH and hMG. Moreover, a Fourier transform infrared microspectroscopy (FTIRM) analysis was performed to evaluate DNA conformational changes in CCs and to relate them with the two COS protocols. The results evidenced a modulation of the expression of miRNAs and related target genes involved in CCs' proliferation, in vasculogenesis, angiogenesis, genomic integrity, and oocyte quality, with different effects according to the ovarian reserve of patients. Moreover, the COS protocols determined differences in DNA conformation and the methylation state. In particular, the results clearly showed that treatment with rFSH is the most appropriate in NR patients with normal ovarian reserve, while treatment with hMG appears to be the most suitable in LR patients with low ovarian reserve.

Keywords: rFSH treatment; hMG treatment; oocyte quality; ovarian reserve; cumulus cells; assisted reproduction technology (ART); DNA conformation; FTIR microspectroscopy

\section{Introduction}

A complex bidirectional communication is observed between the oocyte and the cumulus cells (CCs) that surround it, which not only have trophic functions, but are also involved in the maintenance of the meiotic block of the oocyte during follicular growth [1]. The study of the cumulus-oocyte complex allows one to establish that a 'competent' oocyte cannot exist without a 'competent' cumulus. For this reason, a molecular analysis of the CCs is nowadays considered predictive of oocyte quality [2]. For example, the stage of CC development is associated with the fate of the follicle: their proliferation promotes follicle maturation and ovulation, while their apoptosis causes atresia and follicle degradation [3]. In this light, for proper follicular recruitment, development, and ovulation, somatic and germinal cells within the ovaries need to precisely express specific genes 
in a coordinated fashion [4]. MicroRNAs (miRNAs) represent a class of small (18-22 nt) non-coding, single-stranded RNAs actively regulating the mRNA translation of over $70 \%$ of protein-coding genes, and they are widely involved in both normal and pathological states [5]. MiRNAs' role in ovarian cells has been partially elucidated, and their influence on key ovarian functions such as steroidogenesis, ovulation, and the development and function of the corpus luteum has been discovered [6]. Recent evidence showed the regulatory function of miRNAs in oocyte maturation and ovarian follicular development by promoting granulosa cells proliferation [7-10], or cell apoptosis and the formation of the corpus luteum [11-14]. Thus, understanding the mechanisms underlying the way in which somatic cell miRNAs are regulated and identifying their specific target genes and functions can lead to the development of strategies to achieve specific gene regulation for the prevention and treatment of various ovarian disorders.

Since in ART there is always a need to improve the knowledge of key molecules associated with the development of the embryo, in order to reach advanced diagnostic practices, follicular cells' miRNAs have recently been taken into account as potential reliable biomarkers in level II (in vitro fertilization and embryo transfer, IVF-ET, and intracytoplasmic sperm injection, ICSI) and III ART (testicular sperm aspiration, TESA, testicular sperm extraction, TESE, followed by ICSI) techniques.

In ART practices, over the years, in parallel with the introduction of increasingly targeted and advanced drugs, new protocols and procedures for the personalization of treatments have been developed in order to offer women ovarian stimulation techniques increasingly suited to their individual profile. In the management of infertility, the main hormonal biomarker is the anti-Müllerian hormone (AMH), used as a direct measure of the ovarian state, in order to personalize the treatment as much as possible. According to the European Society of Human Reproduction and Embryology (ESHRE) guidelines (2019), during ovarian stimulation for IVF/ICSI, the use of antral follicle count (AFC) or the quantification of anti-Müllerian hormone (AMH) levels is recommended compared to other ovarian reserve tests $[15,16]$. Although there is no unanimously recognized cut-off, due to the different quantification techniques of this hormone, to stratify patients based on ovarian reserve, in this study, we divided the cohort of patients into patients with low reserve, $\mathrm{LR}(\mathrm{AMH}<1.2 \mathrm{ng} / \mathrm{mL})$ [17], and normal reserve, $\mathrm{NR}(\mathrm{AMH}>1.2-4.0 \mathrm{ng} / \mathrm{mL})$ [18].

Nowadays, several strategies are available to induce ovarian stimulation that differs in the type and dose of gonadotropins administered, and in the mode of suppression of the pituitary gland [19]. An ideal stimulation protocol should reduce risks and side effects, allow for a low cycle cancellation rate, and involve limited endocrine and ultrasound control. Unfortunately, to date, a single protocol capable of possessing all these characteristics has not yet been developed: the advantages and disadvantages must be assessed individually, based on certain characteristics, such as the woman's age, ovarian reserve, and response. One of the most exploited controlled ovarian stimulations (COS) protocols includes treatment with follicle-stimulating gonadotropins, which can be recombinant, indeed synthesized, through genetic engineering techniques (e.g., follitropin $\alpha$, follitropin $\beta$, corifollitropin $\alpha$, and lutropin $\alpha$ ), or menopausal gonadotropins, hence extracted from the urine of postmenopausal women, containing FSH and LH in different proportions (menotropin, or hMG), or containing only FSH (urofollitropin).

The aim of the present study was to elucidate the different responses of low and normal ovarian reserve patients to different ovarian stimulation protocols (recombinant FSH, $\mathrm{rFSH}$, and human menopausal gonadotropin, $\mathrm{hMG}$ ), on the expression of selected miRNA and their target genes, in CCs retrieved by ART patients with normal and low reserves. In this study, the following miRNAs were considered: miR-181a-5p, miR-93-5p, miR-130b-3p, let-7g-5p, and miR-34a-5p. Moreover, the expression of some of their target genes, involved in the regulation of the developmental stage of CCs, including their proliferation, differentiation, and apoptosis, was analysed. In particular, for miR-181a-5p, the genes ACVRIIA (activin receptor type-2A) and SMAD3 (small mother against decapentaplegic 3) were considered. Activin, by binding and activating type II receptors (ACVRIIA), promotes gran- 
ulosa cells' proliferation and follicle growth and [20], in turn, triggers the Smad signalling pathway through the phosphorylation of SMAD3 and the transcription regulation of its target genes. Hence, the activation of this signalling pathway promotes the proliferation of CCs, repressing their apoptosis, while its inhibition can suppress activin-induced differentiation, causing sub-fertility and generating defects in the regulation and differentiation of granulosa cells [12]. For miR-93-5p, CDKN1A (cyclin-dependent kinase inhibitor 1A), encoding a potent cyclin-dependent kinase inhibitor, and CDK2 (cyclin-dependent kinase 2) were examined. The protein encoded by the $C D K N 1 A$ gene binds and inhibits the activity of kinase 2-cyclin-dependent complexes acting as a regulator of cell cycle progression in the G1 phase. It was demonstrated that miR-93-5p, by suppressing CDKN1A expression, promotes cell proliferation, while the reintroduction of $C D K N 1 A$ reverses the proliferative stimulating role of miR-93-5p [21]. SMAD5 (small mother against decapentaplegic 5), on the other hand, was selected as the target gene of miR-130b-3p. Since SMAD proteins are involved in the proliferation of granulosa and cumulus cells [22], the overexpression of miR-130b-3p promotes the viability and proliferation of granulosa and cumulus cells. Furthermore, it was demonstrated that the inhibition of miR-130b-3p expression during in vitro maturation of oocytes reduces polar globule extrusion [10]. In the case of miRNA let-7g-5p, a target gene involved in the TGF- $\beta$ /SMAD signalling pathway was analysed. In fact, it was demonstrated that let-7g-5p promotes the apoptosis of granulosa and cumulus cells targeting TGF $\beta r 1$ [11], which in turn, via the TGF- $\beta$ signalling pathway, modulate the regulation of the expression of SMAD proteins [11]. The expression of miR-34a-5p was analysed in relation to its selected target genes, here represented by vascular endothelial growth factor A (VEGFA), TGF $\beta 1$, and minichromosome maintenance complex component 3 (MCM3). VEGFA is a gene that codes for a glycoprotein belonging to the VEGF family, involved both in vasculogenesis and in angiogenesis, two processes that are essential during the luteinization phase. As previously mentioned, TGF $\beta 1$ is a multifunctional protein that regulates numerous physiological processes through the activation of the TGF- $\beta$ signalling pathway, which seems to be, in turn, on the basis of the vasculogenesis process [23]. MCM3 encodes for the protein maintenance of the mini-chromosome (MCM proteins), necessary for the initiation of the replication process in eukaryotes and the maintenance of genomic integrity [13]. In addition to the miRNAs and target genes mentioned above, miR-202-5p was also analyzed in this study: its target genes identified and analysed in this study are HAS2 (hyaluronan synthase 2) and NLRP2 (NLR family pyrin domain contains 2). HAS2 encodes for an essential enzyme for the synthesis of hyaluronic acid, which represents the structural skeleton of the extracellular matrix of the cumulus and, in turn, is responsible for the expansion of the cumulus oophorus [24]. NLRPs, on the other hand, are members of the NLR (Nod-like receptor) family of proteins. Recently, several NLRPs have been found to be related to reproduction, as several studies on the expression analysis of the NLRP family suggested that many of the genes are expressed specifically in mammalian oocytes [25], and that proteins encoded by them play a crucial role in preimplantation development [26]. Specifically, the NLRP2 inflammasome regulates oocyte quality, and is involved in the decline in fertility associated with age [27]. Furthermore, NLRP2 has been identified as a maternal effect gene required for early embryonic development in mice. In this regard, the regulation of maternal gene expression resulted in determining the procedural embryonic arrest [28]. Figure 1 schematically displays the miRNAs selected for the study, together with their related genes and the biological processes they modulate.

In addition, in CCs collected from patients treated with rFSH or hMG, Fourier transform infrared microspectroscopy (FTIRM) analysis was applied to evidence the DNA conformational changes that appeared to be related with COS treatments. FTIRM is a vibrational technique, widely applied to investigate the biomolecular building and composition of cells and tissues, allowing one to obtain, in a label-free way, the unique molecular fingerprint of the most relevant biological molecules [29,30]. The spectral profiles obtained by the FTIRM analysis can be correlated with biological processes, such as metabolism, stress status, and apoptosis [31-33]. A previous study from our laboratory evidenced the re- 
lationship between the metabolic profile of granulosa cells and the fate of the corresponding oocyte, as assessed by gene expression and Fourier transform infrared microspectroscopy (FTIRM). Recently, FTIRM was also exploited to characterize both human oocytes [34] and granulosa cells [22,35], and to assess the effects on human cumulus cells of three controlled ovarian stimulation protocols, based on urinary FSH, recombinant FSH, or hMG [36]. In particular, FTIRM is able to elucidate possible conformational changes in DNA conformation, by evaluating the relative amounts of B-form, A-form, and Z-form DNAs [33]. For example, the B- to A-form DNA transition has been reported to occur, in a reversible way, upon dehydration, possibly as a mechanism to reduce DNA damages [37]. Besides cells' hydration state, the B- to A-DNA transition also arises, in a non-reversible way, as a response to some drug treatments, especially with compounds interrupting base pairing, like cisplatin $[32,38,39]$. With regard to Z-form DNA, it is a left-handed conformation, the formation of which is facilitated by DNA methylation; hence, it can be found in specific sequences $[40,41]$.

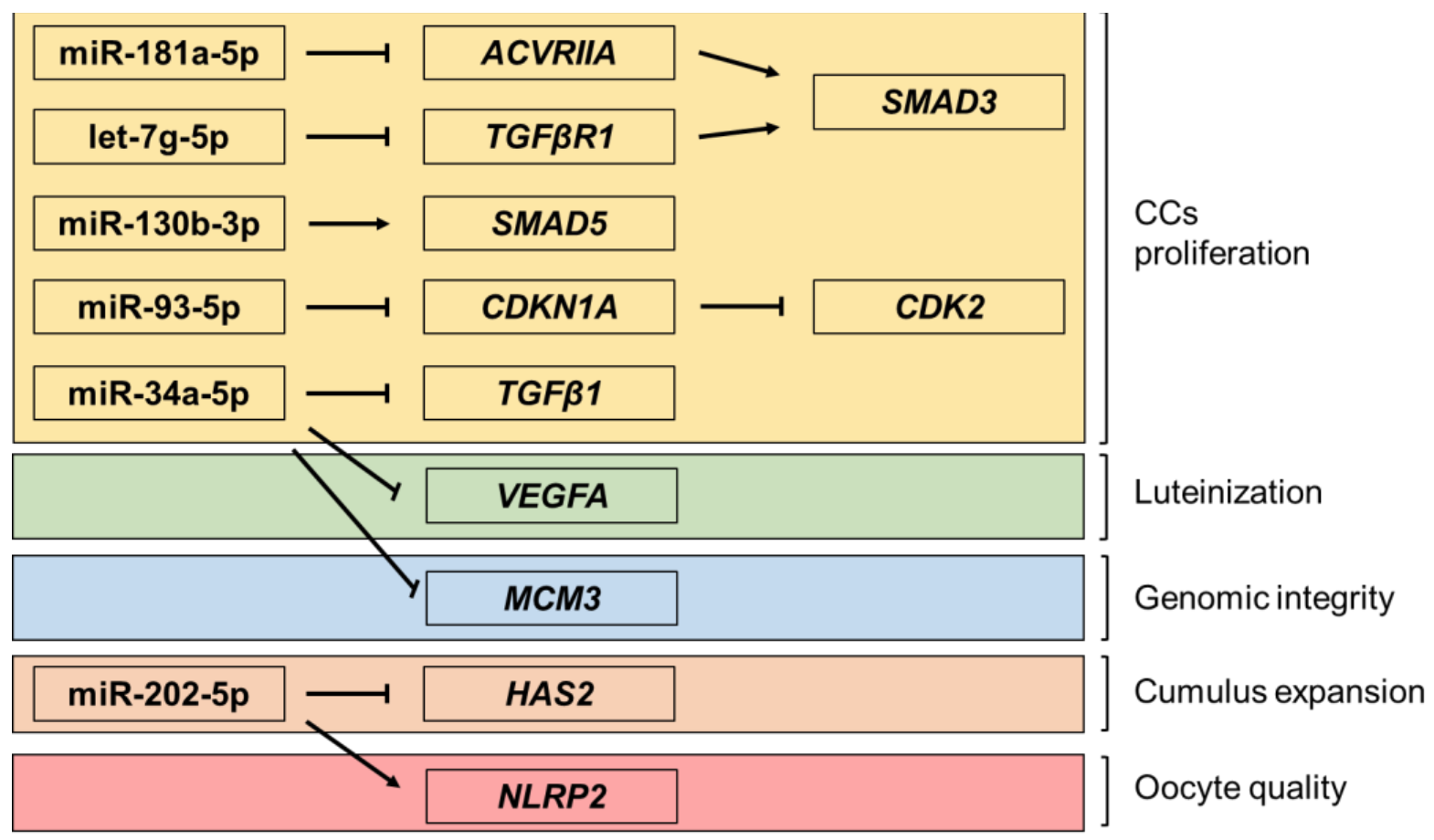

Figure 1. Scheme displaying the miRNAs selected in the study, together with their related genes and the pathways they are involved in. ACVRIIA: activin A receptor type 2A; SMAD3: smad family member 3; TGF $\beta R 1$ : transforming growth factor beta receptor 1; SMAD5: smad family member 5; CDKN1A: cyclin dependent kinase inhibitor 1A; CDK2: cyclin dependent kinase 2; TGF $\beta 1$ : transforming growth factor beta 1; VEGFA: vascular endothelial growth factor; $M C M 3$ minichromosome maintenance complex component 3; HAS2: hyaluronan synthase; NLRP2: NLR family pyrin domain containing 2 .

\section{Results}

\subsection{Patients' Data}

Table 1 reports patient data related to the response to COS treatments: mean number of retrieved oocytes and percentages of mature and fertilized immature oocytes.

Data displayed, as expected, a higher average number of retrieved oocytes in patients with normal ovarian reserve (NR), with respect to those with low ovarian reserve (LR). Within each group, some differences related to the adopted COS protocol were detectable: first, in the NR group, a significantly higher percentage of fertilized oocytes was found in patients treated with $\mathrm{rFSH}$, with respect to those treated with $\mathrm{hMG}$, while no difference was found with regard to the percentages of mature and immature oocytes; to a further 
extent, in the LR group, more marked differences due to the stimulation protocol were visible, with the patients treated with hMG displaying significantly higher percentages of mature oocytes and fertilized oocytes.

Table 1. Summary of patients' data: number of average retrieved oocytes, percentage of immature, mature, and fertilized oocytes. Data of number of retrieved oocytes are reported as mean \pm standard deviation. Different letters indicate a statistically significant difference $(p<0.05)$ and are calculated by ANOVA followed by Tukey's multiple comparisons test (average retrieved oocytes) and by Chi square test (\% immature, $\%$ mature oocytes, and \% fertilized oocytes).

\begin{tabular}{|c|c|c|c|c|c|c|}
\hline Treatment & $\begin{array}{c}\text { \# } \\
\text { Patients }\end{array}$ & $\begin{array}{l}\text { Ovarian } \\
\text { Reserve }\end{array}$ & $\begin{array}{c}\text { Retrieved } \\
\text { Oocytes }\end{array}$ & $\begin{array}{c}\% \text { Immature } \\
\text { Oocytes }\end{array}$ & $\begin{array}{c}\text { \% Mature } \\
\text { Oocytes }\end{array}$ & $\begin{array}{c}\% \text { Fertilized } \\
\text { Oocytes }\end{array}$ \\
\hline \multirow{2}{*}{$r F S H$} & 9 & low & $3.44 \pm 1.88^{a}$ & $21.00 \%{ }^{a}$ & $79.00 \%{ }^{a}$ & $69.45 \%$ a \\
\hline & 18 & normal & $8.06 \pm 4.22^{b}$ & $22.06 \%{ }^{a}$ & $78.00 \%{ }^{a}$ & $78.64 \%$ b \\
\hline \multirow{2}{*}{$h M G$} & 6 & low & $3.00 \pm 1.41^{\mathrm{a}}$ & $8.83 \%$ b & $91.17 \%$ b & $91.67 \%{ }^{c}$ \\
\hline & 18 & normal & $6.33 \pm 3.70^{a b}$ & $28.72 \%{ }^{a}$ & $71.28 \%{ }^{a}$ & $70.00 \%{ }^{a}$ \\
\hline
\end{tabular}

\section{2. miRNA Expression and Gene Target Evaluation in CCs}

The following miRNAs were considered: miR-181a-5p, miR-93-5p, miR-130b-3p, let$7 g-5 p$, and miR-34a-5p, together with some of their target genes, involved in the regulation of the developmental stage of CCs; the used primer sequences are reported in Table 2 (see Materials and Methods section).

Table 2. List of primers used for miRNA and gene expression analyses by real-time qPCR (ACTB: actin beta; RPL13A: ribosomal protein L13a; ACVRIIA: activin A receptor type 2A; SMAD3: SMAD family member 3; CDKN1A: cyclin dependent kinase inhibitor 1A; CDK2: cyclin dependent kinase 2; HAS2: hyaluronan synthase 2; NLRP2: NLR family pyrin domain containing 2; SMAD5: SMAD family member 5; TGFBR1: transforming growth factor beta receptor 1; VEGFA: vascular endothelial growth factor A; TGFB1: transforming growth factor beta 1).

\begin{tabular}{|c|c|c|c|}
\hline miRNA & $\begin{array}{l}\text { Forward Primer } \\
\qquad\left(5^{\prime}-3^{\prime}\right)\end{array}$ & $\begin{array}{c}\text { Universal Reverse } \\
\text { Primer }\left(5^{\prime}-3^{\prime}\right)\end{array}$ & miRBase Accession Number \\
\hline$m i R-181 a-5 p$ & AACATTCAACGCTGTCGGTGAGT & GCGAGCACAGAATTAATACG & MI0000269 \\
\hline$m i R-93-5 p$ & CAAAGTGCTGTTCGTGCAGGTAG & GCGAGCACAGAATTAATACG & MI0000095 \\
\hline$m i R-23 a-5 p$ & GGGGTTCCTGGGGATGGGATTT & GCGAGCACAGAATTAATACG & MI0000079 \\
\hline$m i R-202-5 p$ & TTCCTATGCATATACTTCTTTG & GCGAGCACAGAATTAATACG & MI0003130 \\
\hline$m i R-130 b-3 p$ & CAGTGCAATGATGAAAGGGCAT & GCGAGCACAGAATTAATACG & MI0000748 \\
\hline let-7g-5p & TGAGGTAGTAGTTTGTACAGTT & GCGAGCACAGAATTAATACG & MI0000433 \\
\hline$m i R-34 a-5 p$ & TGGCAGTGTCTTAGCTGGTTGT & GCGAGCACAGAATTAATACG & MI0000268 \\
\hline Gene & Forward Primer $\left(5^{\prime}-3^{\prime}\right)$ & Reverse Primer $\left(5^{\prime}-3^{\prime}\right)$ & NCBI Accession Number \\
\hline$A C T B$ & GCAGAAGGAGATCACATCCCTGGC & CATTGCCGTCACCTTCACCGTTC & NM_001101.5 \\
\hline$R P L 13 A$ & TCTGGAGGACTGTAAGAGGTATGC & AGACGCACAATCTTGAGAGCAG & NM_012423.3 \\
\hline ACVRIIA & CCTCGGACTTTAGGTGTCTGG & CCAAGTATAGCACCTGAAGAACA & NM_001278579.2 \\
\hline SMAD3 & GCCTGTGCTGGAACATCATC & TTGCCCTCATGTGTGCTCTT & NM_005902.4 \\
\hline CDKN1A & AGGTGGACCTGGAGACTCTCAG & TCCTCTTGGAGAAGATCAGCCG & NM_000389.5 \\
\hline CDK2 & ATGGATGCCTCTGCTCTCACTG & CCCGATGAGAATGGCAGAAAGC & NM_001798.5 \\
\hline HAS2 & GTCATGTACACAGCCTTCAGAGC & ACAGATGAGGCTGGGTCAAGCA & NM_005328.3 \\
\hline NLRP2 & CATTCTGCGTCAAGCACTGTCG & CCGTCCAGAAAGGAAGCATGTG & NM_001348003.2 \\
\hline SMAD5 & CAGGAGTTTGCTCAGCTTCTGG & GGTGCTGGTTACATCCTGCCG & NM̄005903.7 \\
\hline TGFBR1 & GACAACGTCAGGTTCTGGCTCA & CCGCCAСТTTССТСТССАААСТ & NM_004612.4 \\
\hline VEGFA & TTGCCTTGCTGCTCTACСTCCA & GATGGCAGTAGCTGCGCTGATA & NM_001025366.3 \\
\hline TGFB1 & GCCGTGGAGGGGAAATTGAG & TGAACCCGTTGATGTCCACTT & NM_000660.7 \\
\hline MCM3 & CGAGACCTAGAAAATGGCAGCC & GCAGTGCAAAGCACATACCGCA & NM_002388.6 \\
\hline
\end{tabular}

Figure 2 reports the modulation of miR-181a-5p determined in CCs by two different COS treatments patients with normal ovarian reserve (NR) and low ovarian reserve (LR), together with the expression of ACVRIIA and SMAD3. As the graphs show, ovarian stimulation performed with recombinant FSH determines, in patients with low ovarian reserve, a high expression of the miRNA of interest, which is reflected in a lower expression 
of the activin IIa receptor; a lower expression of the SMAD3 gene was also found in LR patients treated with $\mathrm{rFSH}$, with respect to NR ones. With regard to the treatment based on hMG administration, it determined in LR patients a significantly reduced expression of miR-181a-5p, which was reflected in the significantly higher expression of ACVRIIA.
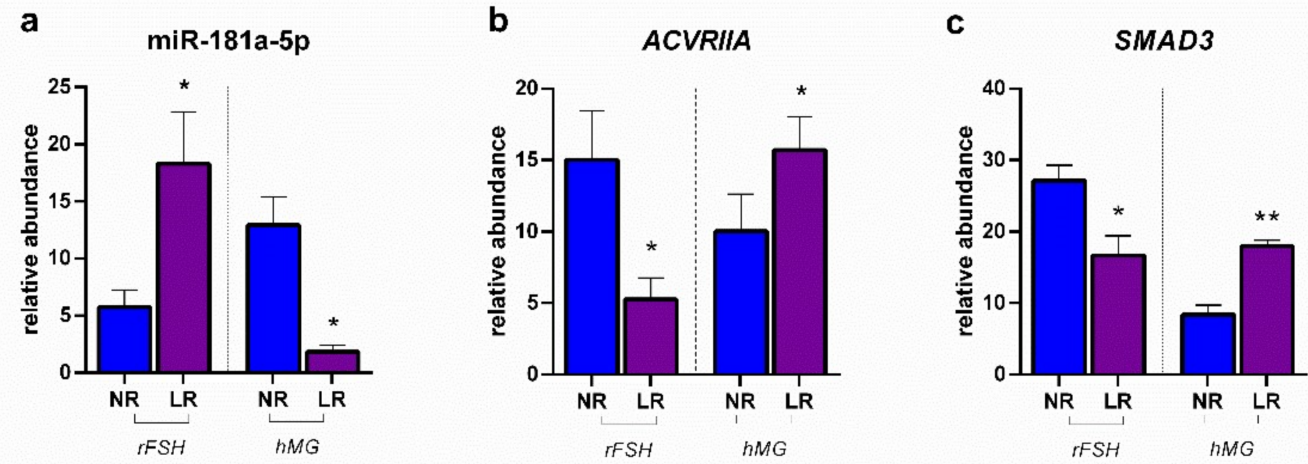

Figure 2. Expression profiles: (a) miR-181a-5p; (b) ACVRIIA: activin A receptor type 2A; (c) SMAD3: smad family member 3 . Results are reported as mean \pm standard deviation. Statistical significance was set at $p<0.05$ and calculated by Student's $t$-test. Asterisks above columns indicate statistical differences between NR and LR groups. ${ }^{*}=p<0.05 ;{ }^{* *}=p<0.01$.

Figure 3 reports the modulation of miR-93-5p determined in CCs by the two examined COS treatments in NR and LR patients, together with the expression of CDKN1A and CDK2. The results showed a significantly lower expression of miR-93-5p in LR patients treated with $\mathrm{rFSH}$, with respect to NR, which was reflected in a higher expression of the CDKN1A target gene, and, subsequently, in a lower expression of CDK2, in turn, a target of CDKN1A. Conversely, as a response to the COS treatment based on hMG, the expression of miR-93-5p was significantly higher in LR patients with respect to NR, leading to a lower expression of CDKN1A and a higher expression of CDK2.

a

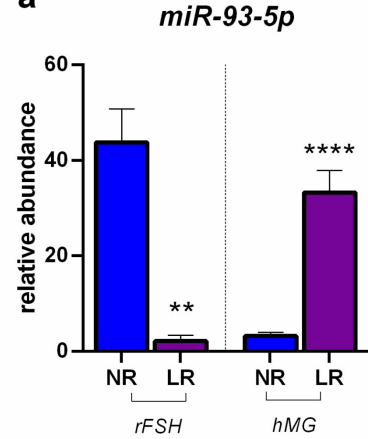

b

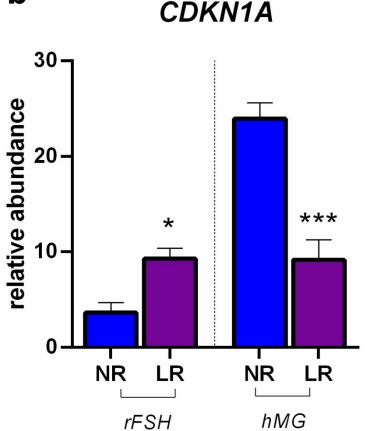

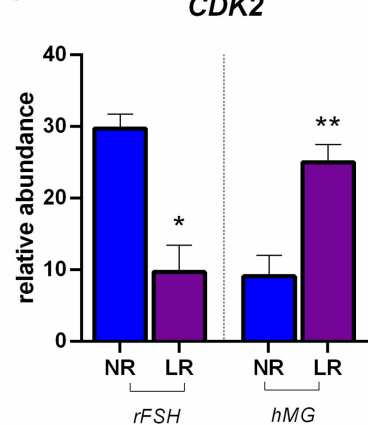

Figure 3. Expression profiles: (a) miR-93-5p; (b) CDKN1A: cyclin dependent kinase inhibitor 1A; (c) $C D K 2$ : cyclin dependent kinase 2. Results are reported as mean \pm standard deviation. Statistical significance was set at $p<0.05$ and calculated by Student's $t$-test. Asterisks above columns indicate statistical differences between NR and LR groups. ${ }^{*}=p<0.05 ;{ }^{* *}=p<0.01 ;{ }^{* * *}=p<0.001$; ${ }^{* * * * *}=p<0.0001$

Figure 4 reports the modulation of miR-130b-3p determined in CCs by the two different COS treatments in NR and LR patients, together with the expression of SMAD5. No statistically significant difference was found between NR and LR patients treated with rFSH in terms of miR-130b-3p expression, while the hormonal treatment based on hMG revealed significantly higher values in LR patients. SMAD5 expression showed the same expression profile as miR-130b-3p. 
a

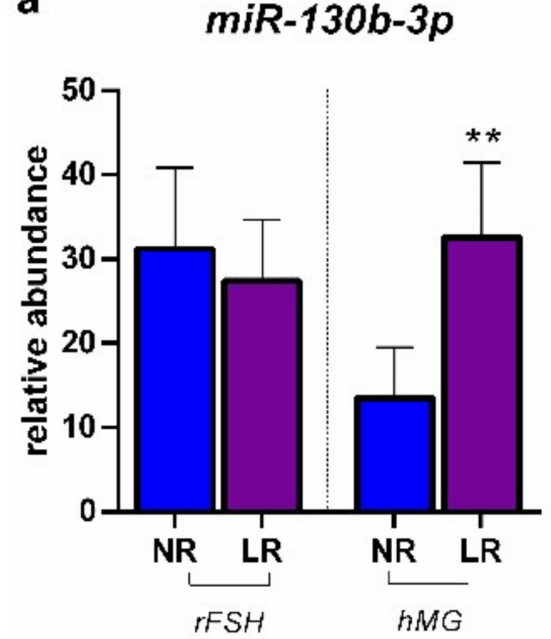

b

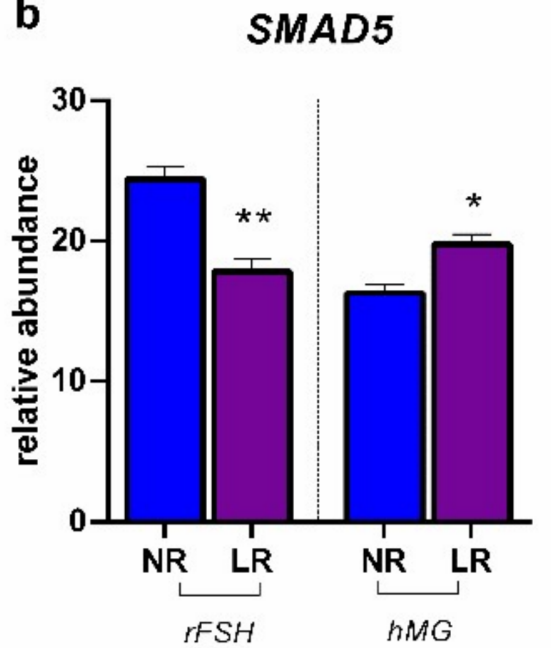

Figure 4. Expression profiles: (a) miR-130b-3p; (b) SMAD5: smad family member 5. Results are reported as mean \pm standard deviation. Statistical significance was set at $p<0.05$ and calculated by Student's $t$-test. Asterisks above columns indicate statistical differences between NR and LR groups. * $=p<0.05 ;{ }^{* *}=p<0.01$.

Figure 5 reports the modulation of let-7g-5p in CCs determined by the two different COS treatments in NR and LR patients, together with the expression of TGFBR1. The results revealed that the rFSH treatment determined a significantly higher expression of let-7g-5p in LR patients, with respect to NR ones, leading to a significantly lower expression of TGFBR1. On the contrary, the administration of $\mathrm{hMG}$ resulted in a significantly lower expression of the miRNA of interest in LR patients, consequently leading to the reduced expression of the target gene TGFBR1. In both cases, these results are consistent with a high expression of the TGF- $\beta$ type I receptor, fundamental for the activation of the TGF- $\beta$ /SMAD signal transduction pathway. TGF $\beta R 1$, in fact, will initiate the intracellular transduction of the signal through the phosphorylation of R-smad, represented, in our case, by SMAD3 (see Figure 1).

a

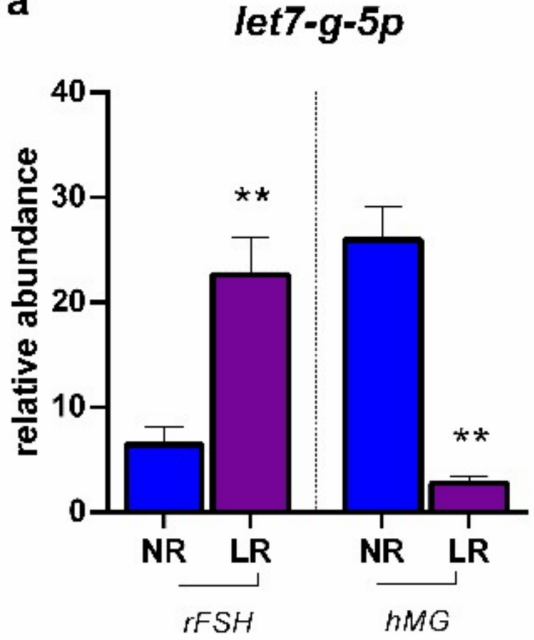

b

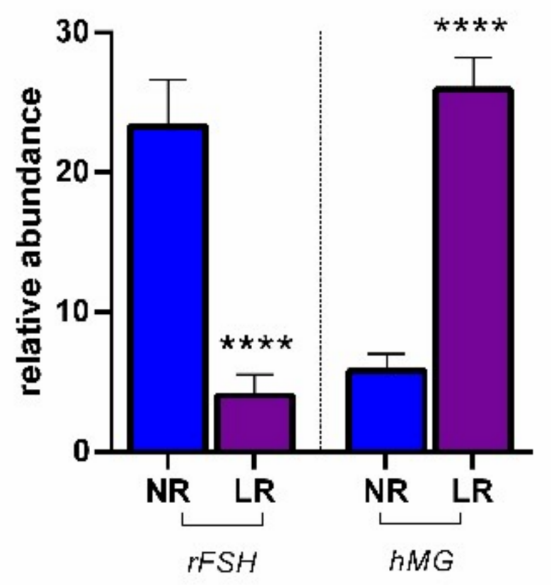

Figure 5. Expression profiles: (a) let-7g-5p; (b) TGF $\beta R 1$ : transforming growth factor beta receptor 1 . Results are reported as mean \pm standard deviation. Statistical significance was set at $p<0.05$ and calculated by Student's t-test. Asterisks above columns indicate statistical differences between NR and LR groups. ${ }^{* *}=p<0.01 ; * * * *=p<0.0001$. 
Figure 6 reports the modulation of miR-34a-5p determined by the two different COS treatments in NR and LR patients, together with the expression of VEGFA, TGFB1, and MCM3. Data revealed the contrasting response of NR and LR patients to the COS treatment: in fact, the administration of $r F S H$ resulted in significantly higher values of miR-34a-5p expression, consistently leading to a lower expression of TGFB1 and MCM3 (VEGFA showed no significant difference between NR and LR treated with $\mathrm{rFSH}$ ). The treatment with $\mathrm{hMG}$ determined a lower expression of the miRNA of interest in LR patients with respect to NR ones, together with a higher expression of TGFB1, VEGFA, and MCM3.

a

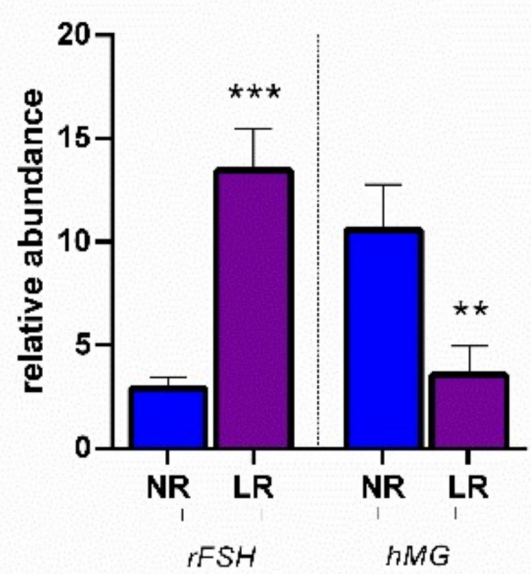

C

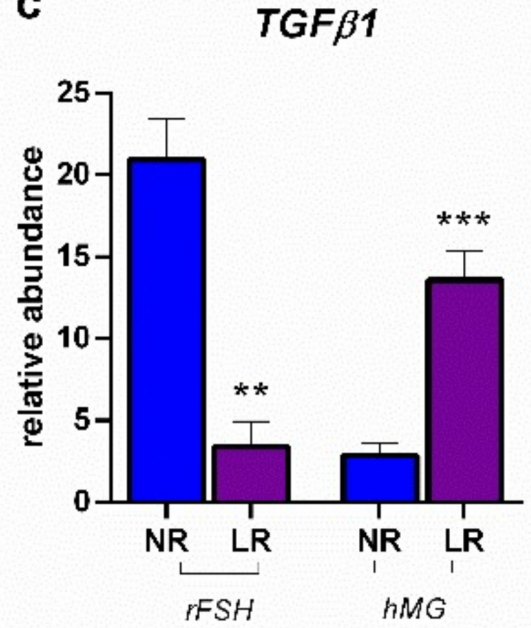

b

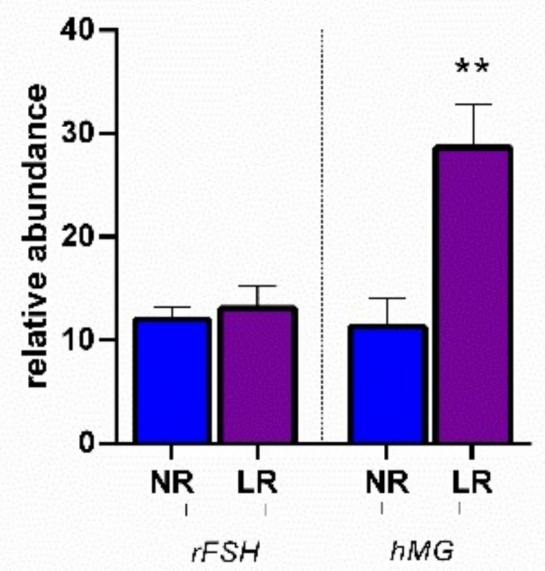

d

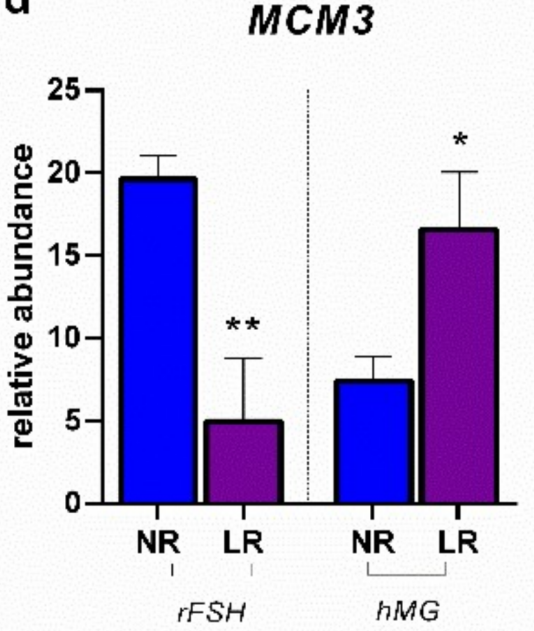

Figure 6. Expression profiles: (a) miR-34a-5p; (b) VEGFA: vascular endothelial growth factor; (c) TGF $\beta 1$ : transforming growth factor beta 1 ; (d) MCM3 minichromosome maintenance complex component 3 . Results are reported as mean \pm standard deviation. Statistical significance was set at $p<0.05$ and calculated by Student's t-test. Asterisks above columns indicate statistical differences between NR and LR groups. ${ }^{*}=p<0.05 ;{ }^{* *}=p<0.01 ;{ }^{* * *}=p<0.001$.

Figure 7 reports the modulation of miR-202-5p determined in CCs by the two different COS treatments in NR and LR patients, together with the expression of its target genes, HAS2 and NLRP2. The treatment of poor responders with hMG and normal responders with $\mathrm{rFSH}$ showed the inhibition of miR202-5p and NLRP2 expression, together with an induction of HAS2 expression. 
a

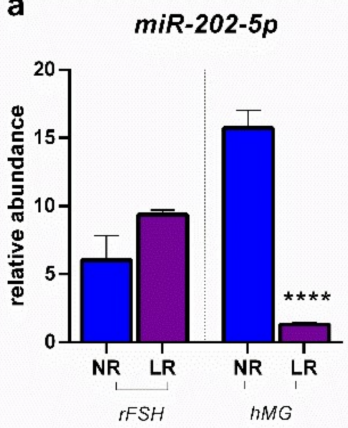

b

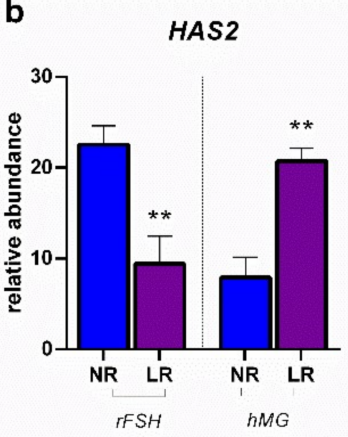

C

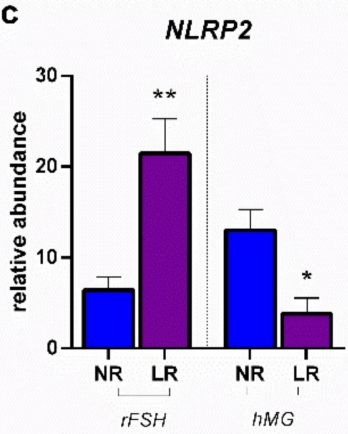

Figure 7. Expression profiles: (a) miR-202-5p; (b) HAS2: hyaluronan synthase; (c) NLRP2: NLR family pyrin domain containing 2 . Results are reported as mean \pm standard deviation. Statistical significance was set at $p<0.05$ and calculated by Student's t-test. Asterisks above columns indicate statistical differences between NR and LR groups. ${ }^{*}=p<0.05{ }^{* *}=p<0.01{ }^{* * * *}=p<0.0001$.

\subsection{FTIRM Analysis}

CC samples of women treated with $\mathrm{rFSH}$ or hMG stimulation protocols were then analyzed by FTIRM, in order to assess the effects of COS treatments on the spectral profile of the nucleic acid component.

Figure 8a displays the second derivatives of the average spectra of CCs from NR and LR patients treated with $\mathrm{rFSH}$ and NR and LR patients treated with hMG. Second derivatives were exploited to precisely identify the subpeaks of IR bands by means of the curve fitting procedure. The peaks of interest are reported in Table 3 (see Materials and Methods section), in terms of wavenumbers, vibrational modes, and biochemical assignments.
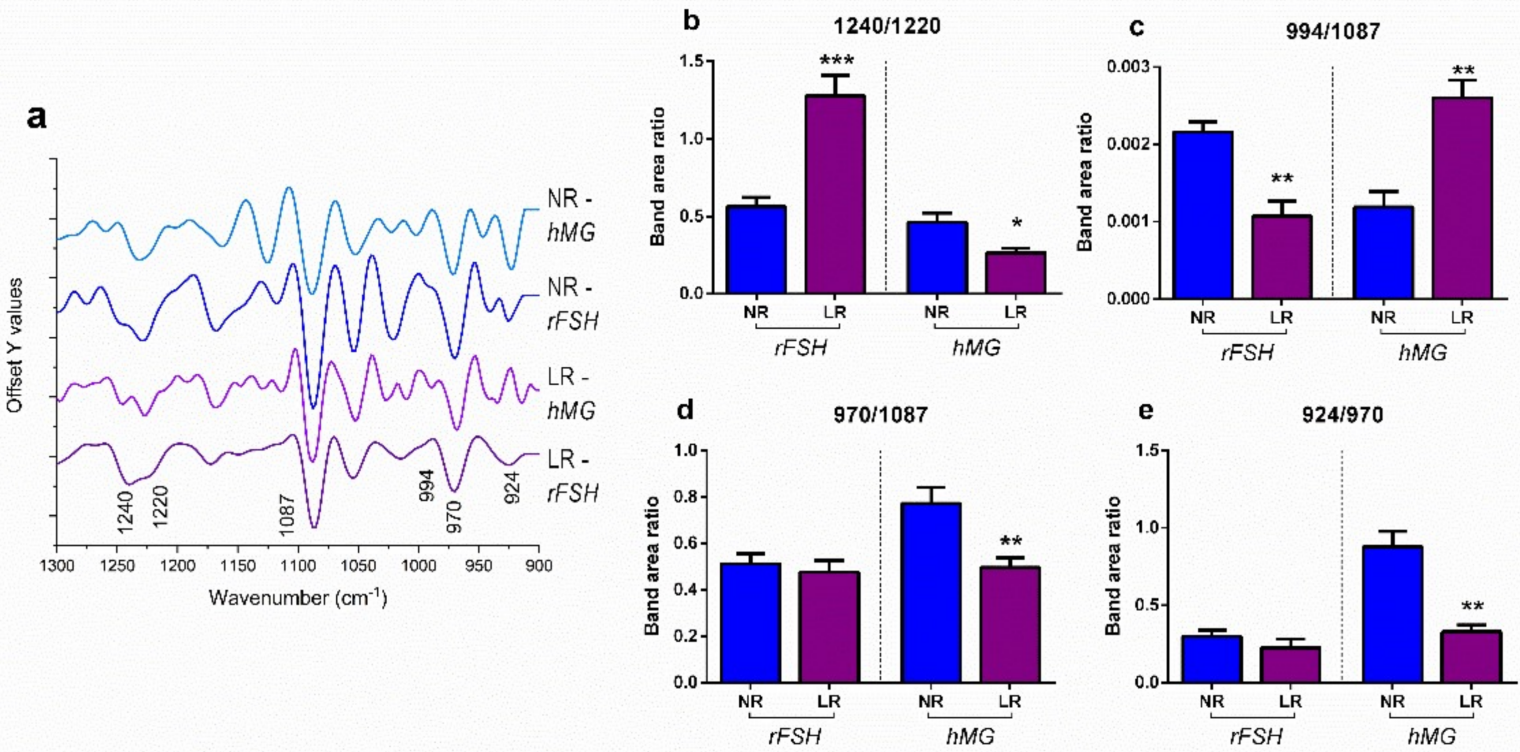

Figure 8. (a) Average spectra of NR and LR groups, treated with $\mathrm{rFSH}$ and $\mathrm{hMG}$, reported in second derivative mode (1300-900 $\mathrm{cm}^{-1}$ ); the wavenumbers of the most relevant peaks are labelled at the bottom. Results of Student's $t$-test on band area ratios (b) 1240/1220, (c) 994/1087, (d) 970/1087, and (e) $924 / 970$. Histograms show the values of the band area ratios obtained by curve fitting procedure on mean spectra and the mean \pm standard deviation spectra of NR and LR groups, treated with $\mathrm{rFSH}$ and $\mathrm{hMG}$. Data are reported as mean \pm standard deviation. Statistical significance was set at $p<0.05$ and calculated by Student's $t$-test. Asterisks above columns indicate a statistically significant difference between NR and LR groups. ${ }^{*}=p<0.01 ;{ }^{* *}=p<0.01 ;{ }^{* * *}=p<0.001$. 
Average absorbance spectra of NR and LR patients treated with rFSH or hMG CC samples and their average \pm standard deviation spectra were curve-fitted. Specific band area ratios were calculated and analyzed (Figure $8 b-e$ ). Nucleic acids' relative quantity and characteristics appeared to be affected by the different ovarian stimulation protocols: DNA conformation was affected, in terms of the ratio between the disordered A-form DNA and the ordered B-form DNA (1240/1220 band area ratio), especially in CCs from rFSH-treated LR patients, with respect to NR ones (Figure $8 b$ ); the amount of RNA, with respect to total nucleic acids (994/1087 band area ratio), resulted in significantly higher CCs from hMG-treated LR patients and rFSH-treated NR patients (Figure 8c); the amount of double-stranded DNA, with respect to total nucleic acids (970/1087 band area ratio), resulted in being statistically comparable between NR and LR patients treated with $\mathrm{rFSH}$, while significantly higher values were found in CCs from hMG-treated NR patients, with respect to LR ones (Figure 8d). The amount of left-helix DNA (or Z-DNA), with respect to total double-stranded DNA (924/970 band area ratio), resulted in being statistically comparable between NR and LR patients treated with $\mathrm{rFSH}$, while significantly lower values were found in CCs from LR patients treated with hMG, with respect to NR ones (Figure 8e).

\section{Discussion}

In ART practice, the assessment of ovarian reserve is a fundamental aspect to consider in order to select the most appropriate controlled ovarian stimulation protocol and to optimize folliculogenesis. Generally, induction protocols include the employment of FSH, $\mathrm{LH}$, and GnRH analogues with agonist or antagonist action [42]. The choice of stimulation protocols must be characterized based on the benefits or disadvantages that they can bring to the single patient.

The clinical activity of in vitro fertilization is based on the ability of ovarian markers to be able to predict the response to ovarian stimulation. The aim of this study, in fact, is to evaluate the impact of different stimulation protocols on specific miRNAs and their associated target genes, which are known to be important regulators of granulosa and cumulus cells' function, both in normal reserve (NR) and low reserve (LR) patients.

Among patients treated with $\mathrm{rFSH}$, a significantly higher number and a higher fertilization rate of retrieved oocytes were found in NR patients, with respect to LR ones. Conversely, among patients treated with $\mathrm{hMG}$, a significantly higher percentage of mature and fertilized oocytes was found in LR patients, with respect to NR ones. These results suggest the different response of patients to the hormonal treatments, which can be related to the activation of different molecular pathways.

The present study also evidenced that the two stimulation protocols induced in CCs a differential expression of miR-181a-5p, let-7g-5p, and miR-34-5p, which are involved in the suppression of cell proliferation and thus in follicle apoptosis.

In the present study, ovarian stimulation performed with rFSH determines, in LR patients, a high expression of miR-181a-5p, and a lower expression of the two selected genes ACVRIIA and SMAD3. These results are in accordance with those previously published, demonstrating that in mice granulosa cells, miR-181a-5p suppresses ACVRIIA expression, and in turn modulates granulosa cells proliferation and ovarian follicle development, using Smad2/3 [43]. In addition, $\mathrm{rFSH}$ seems to interfere with the activin signaling pathway and with the mechanisms regulating CCs proliferation and follicular growth in LR patients. This is consistent with the lower number of retrieved oocytes with respect to NR. Conversely, NR patients treated with $h M G$ were characterized by a lower expression of miR-181a-5p and a higher expression of ACVRIIA, with respect to LR patients.

In the present study, it can be assumed that the treatment with $\mathrm{hMG}$ has a positive effect on LR patients, as suggested by the lower expression of miRNA let-7g-5p and the higher expression of the TGF- $\beta$ type I receptor, responsible for the intracellular transduction of $S M A D 3$ [11]. Conversely, $\mathrm{rFSH}$ is more effective for NR patients, as evidenced by the higher level of both the TGFBR1 receptor and SMAD3. 
The expression levels of miR-34-5p, regulating (i) TGF $\beta 1$, essential for the modulation of CCs proliferation [23], (ii) VEGFA, involved in the luteinization process [44] and (iii) MCM3 crucial in the maintenance of genomic integrity [13], showed that rFSH treatment is the most appropriate for NR patients, while hMG treatment appears to be the most promising in LR patients. Consistent with the results previously obtained, the expression levels of miR-93-5p and miR-130b-3p confirmed that the treatment with rFSH is the most effective for NR patients, while hMG is more suitable for LR patients. In fact, in the present study, a higher expression of miR-93-5p in LR patients treated with hMG and in NR patients treated with rFSH was observed. This result was related to a lower expression of the CDKN1A gene that encodes for the kinase inhibitor, and, in turn, a higher expression of the CDK2 gene involved in the progression of the cell cycle [21]. No significant change in miR-130b-3p expression was found between NR and LR patients treated with rFSH. On the contrary, miR-130b-3p levels were higher in LR patients with respect to NR treated with hMG. SMAD5 involved in promotion of CCs proliferation, selected as the target gene of miR-130b-3p, showed a similar expression profile in both groups after $\mathrm{rFSH}$ and $\mathrm{hMG}$ treatments. These results evidenced that $\mathrm{rFSH}$ is more efficient in NR patients, while hMG performs better in LR patients.

In addition to the miRNAs and target genes mentioned above, miR-202-5p and its target genes HAS2 (hyaluronan synthase 2) and NLRP2 (Nod-like receptor family pyrin domain contains 2) were analyzed. miR-202-5p showed a higher expression level in LR patients treated with $\mathrm{rFSH}$, with respect to NR ones, and in NR patients treated with hMG, with respect to LR ones. The subsequent expression profiles of HAS2 and NLRP2, respectively, positively and negatively correlated with oocyte quality, confirm the positive effect of the rFSH treatment on NR patients, and of hMG on LR patients.

A vibrational analysis of nucleic acids' relative quantity and conformation was performed by FTIR microspectroscopy. The high transcriptional activity suggested by the analysis of 994/1087 band area ratio in LR patients treated with hMG and NR ones treated with $\mathrm{rFSH}$, indicated a higher proliferation rate of CCs, with respect to LR patients treated with $\mathrm{rFSH}$, and NR patients treated with hMG. The low level of RNA in these two latter groups seemed to be caused by two different mechanisms: first, the LR patients treated with rFSH displayed the highest values of the 1240/1220 band area ratio, which indicates high amounts of the unordered A-form DNA, which is less efficiently transcribed [32,38,39]; second, in NR patients treated with $\mathrm{hMG}$, the lower transcriptional levels may be associated with the highest levels of the $924 / 970$ band area ratio, representative of the Z-DNA amount. Z-DNA is a left-handed conformation of DNA, often found in specialized sequences as a result of DNA methylation processes, which strongly influences the transcriptional activity via the exclusion of transcription factors $[33,40,41,45]$. Hence, the different stimulation treatment in ART patients with normal and low ovarian reserve seems to determine a change in the conformational state of the CCs DNA; in particular, the different order (A-DNA and B-DNA) and the methylation state (Z-DNA) $[33,37,46]$, representing the real novelty of this study.

\section{Materials and Methods}

\subsection{Ethical Approval}

The study, approved by the ethics committee n. 2020241, was carried out in full accordance with ethical principles for experiments involving humans, including The Code of Ethics of the World Medical Association (Declaration of Helsinki, 2013). Patients participating in the investigation signed a written informed consent agreement, which included the donation of CCs. All samples were strictly anonymous, making it impossible to correlate them to patients.

\subsection{Patient Enrolment and Experimental Design}

A cohort of 51 women was enrolled in an IVF program, according to specific inclusion criteria: women with idiopathic infertility and/or tubal infertility; Mediterranean diet, no 
smoking, no consumption of alcohol, and no consumption of drugs. Exclusion criteria for the cohort selection were: hyper responders, pelvic endometriosis, previous ovarian surgery, presence of ovarian masses, pelvic inflammatory disease, autoimmune or chronic systemic diseases. Women were divided into two groups, according to their serum levels of antiMüllerian hormone (AMH): patients with normal ovarian reserve (NR; n. 36; age 36.25 \pm 3.09 ) had AMH levels of 1.2-4.0 ng/mL [18], while patients with low ovarian reserve (LR; n. 15; age $40.77 \pm 2.62$ ) had AMH levels $<1.2 \mathrm{ng} / \mathrm{mL}$ [17].

After patients' selection and division into NR and LR groups, two different folliclestimulated gonadotropins were administered:

1. Twenty-seven patients (9 LR and $18 \mathrm{NR}$ ) treated with $\mathrm{rFSH}$ formulation $\rightarrow$ Follitropin $\alpha$ and $\beta$ : these are recombinant molecules of the natural human follicle stimulating hormone (Puregon ${ }^{\circledR}$, MSD, Roma, Italy; Gonal- $F^{\circledR}$, Merck, Darmstadt, Germany; Ovaleap $^{\circledR}$, Theramex, London, UK).

2. Twenty-four patients (6 LR and $18 \mathrm{NR}$ ) treated with $\mathrm{FSH}+\mathrm{LH}$ formulation $\rightarrow$ Menotropin (hMG): is a highly purified preparation of FSH and LH in a 1:1 ratio, extracted from the urine of postmenopausal women (Meropur ${ }^{\circledR}$, Ferring, Sweden).

For all the experimental groups, the short protocol of gonadotropin COS was used (daily subcutaneous injection started on the second day of the menstrual cycle), GnRH antagonist (Cetrotide, Merck, Darmstadt, Germany; Orgalutran, MSD, Roma, Italy) was administered on initiation by a follicle of 12-14mm, and HCG 10.000 UI was used for ovulation triggering $36 \mathrm{~h}$ before oocyte retrieval. The gonadotropin doses for patients included in the study were statistically comparable. Moreover, during COS, an ultrasound transvaginal scan (DC-70, Mindray Medical Italy S.R.L., Italy) for follicular growth monitoring was performed.

\subsection{CCs Samples Collection and Preparation}

Oocyte collection was carried out under echographic control, with the use of a needle (Ovum aspiration needle $37 \mathrm{ga}-35 \mathrm{~cm}$, COOK Medical, Bloomington, IN, USA) filled with buffered medium (Flushing Medium with Heparin $10 \mathrm{IU} / \mathrm{mL}$ ) and applied to a transvaginal probe, in order to aspirate follicular fluid and retrieve oocytes. Follicular fluid was recovered in a test tube, $37^{\circ} \mathrm{C}$-maintained, and then poured in a Petri dish (Thermo Fisher Scientific Inc., Waltham, MA, USA) for visualization by a stereomicroscope (Stemi 508, provided with a Thermo plate; ZEISS, Oberkochen, Germany), to identify the cumulus and oocyte cells' complexes (COCs). COCs were washed with a buffered medium at $37^{\circ} \mathrm{C}$ (Flushing Medium, Origio, CooperSurgical, Denmark) and subsequently transferred into an incubator, and into a culture dish (Thermo Fisher Scientific Inc., Waltham, MA, USA) with an unbuffered and pre-equilibrated culture medium at $37^{\circ} \mathrm{C}$.

In order to remove CCs and denudate oocytes, one of the four wells of the IVF-4-Well Dish (Thermo Fisher Scientific Inc., USA) was filled with $150 \mu \mathrm{L}$ of pre-warmed $\left(37^{\circ} \mathrm{C}\right)$ buffered culture medium (Flushing Medium, Origio, CooperSurgical, Målov, Denmark) and $150 \mu \mathrm{L}$ of pre-warmed $\left(37^{\circ} \mathrm{C}\right)$ SynVitro Hyadase (Origio, CooperSurgical, Målov, Denmark); the other three wells were filled with only pre-warmed $\left(37^{\circ} \mathrm{C}\right)$ buffered culture medium. COCs were placed in the well with SynVitro Hyadase and gently aspirated up and down by a denuding pipette (Flexipet ${ }^{\circledR}$ denuding pipette, COOK Medical, Bloomington, IN, USA). Oocytes were transferred into a well rinsed with culture medium, and the remaining cumulus cells were removed. Oocytes were assessed for nuclear maturity: oocytes with the extruded first polar body were considered mature (metaphase II, MII); both oocytes at the germinal vesicle $(\mathrm{GV})$ stage and metaphase I (MI) stage were generally taken into account as "immature". In order to remove the culture medium and prepare cells for further analyses, CC samples were centrifuged at $1000 \times g$ for $15 \mathrm{~min}$ and washed using physiologic salt solution (Merck, Germany); the procedure has been repeated twice. The final CCs pellet was resuspended in $500 \mu \mathrm{L}$ of a physiologic salt solution, and divided according to the subsequent analyses: $10 \mu \mathrm{L}$ of the cell suspension was fixed in a $4 \%$ paraformaldehyde (PFA) solution for $10 \mathrm{~min}$, washed twice in a physiological salt solution, and then stored at 
$4{ }^{\circ} \mathrm{C}$ until FTIR measurements; the remaining cells were centrifuged, and the pellet was stored at $-80^{\circ} \mathrm{C}$ until gene expression analysis.

\subsection{Total RNA Extraction and cDNA Synthesis}

From each CCs sample, small ( $<200 \mathrm{bp}$ ) and total ( $>200 \mathrm{bp})$ RNA fractions were extracted using the miRNeasy Mini Kit ${ }^{\circledR}$ (Qiagen, Hilden, Germany) extraction kit, following the manufacturer's protocol. Total RNA extracts were eluted in $30 \mu \mathrm{L}$ of RNAse-free water. Final RNA concentrations were determined with a NanoDrop ${ }^{\mathrm{TM}} 1000$ Spectrophotometer (Thermo Fisher Scientific Inc., Waltham, MA, USA), and RNA integrity was verified by Gel Red (Biotium Inc., Fremont, CA, USA) staining of $28 \mathrm{~S}$ and $18 \mathrm{~S}$ ribosomal RNA fragments on $1 \%$ agarose gel. RNA was stored at $-80^{\circ} \mathrm{C}$ until use. Total RNA was treated with DNAse (10 IU at $37^{\circ} \mathrm{C}$ for $10 \mathrm{~min}$, Thermo Fisher Scientific Inc., Waltham, MA, USA). An aliquot of $100 \mathrm{ng}$ of each RNA sample was polyadenylated with E.coli poly(A) polymerase (New England Biolabs) and converted into cDNA with the SuperScript-II cDNA Synthesis Kit (Invitrogen, Thermo Fisher Scientific Inc., Waltham, MA, USA), primed with an oligo dT adaptor [47].

\subsection{Real-time Polymerase Chain Reaction}

For each selected miRNA sequence, the primers couple was selected as follows: the forward primer spanned the entire mature sequence and the reverse universal primer was complementary to the poly(T) adaptor [47]. The relative quantification of gene expression was performed with the SYBR Green method in a CFX96 Real-Time PCR system (Bio-Rad, Hercules, CA, USA). PCR was carried out in duplicate for each analyzed sample. Reactions were set by mixing $1 \mu \mathrm{L}$ diluted (1/10) cDNA, $5 \mu \mathrm{L}$ of $2 \times$ SYBR Green PCR Master Mix (BioRad, USA), containing SYBR Green as a fluorescent intercalating agent, $0.2 \mu \mathrm{M}$ of forward and reverse primers, and $3.8 \mu \mathrm{L}$ of Milli-Q water. The thermal profile was as follows: enzyme activation at $95^{\circ} \mathrm{C}$ for $3 \mathrm{~min} ; 45$ cycles of denaturation $\left(10 \mathrm{~s}\right.$ at $\left.95^{\circ} \mathrm{C}\right)$, followed by 20 -s annealing at $60^{\circ} \mathrm{C}$ for all the examined miRNAs and genes, and 20-s elongation at $72{ }^{\circ} \mathrm{C}$. Fluorescence was monitored at the end of each cycle. Dissociation curves for primer specificity and absence of primer-dimer formation check were performed and consistently showed a single peak. Ribosomal protein L13a (RPL13A) and $\beta$-actin (ACTB) were used as internal controls to enable result standardization by eliminating variations in mRNA and cDNA quantity and quality [48]. These genes were chosen because their mRNA levels did not vary between experimental groups. No amplification products were observed in negative controls and no primer-dimer formations were observed in the control templates. Data were analyzed using CFX Manager Software version 3.1 (Bio-Rad, USA). The quantification method was based on a $\Delta \Delta \mathrm{Ct}$ calculation implemented with the Pfaffl equation, to improve accuracy by accounting for varied reaction efficiencies depending on primers $[49,50]$. The modification of gene expression is represented with respect to zero. The target genes for each miRNA of interest were selected by means of the DIANA-TarBase v8 software [51]. The used primer sequences are reported in Table 2.

\subsection{FTIRM Analysis}

FTIRM measurements were performed at the Laboratory of Advanced Research Instrumentation, Department of Life and Environmental Sciences, Università Politecnica delle Marche (Ancona, Italy). A Hyperion 3000 Vis-IR microscope equipped with a $\mathrm{HgCdTe}$ (MCT_A) detector and coupled with an INVENIO interferometer (Bruker Optics, Ettlingen, Germany) was used.

An aliquot of $10 \mu \mathrm{L}$ of CCs from each patient was deposited onto $\mathrm{CaF}_{2}$ optical windows (1-mm thick, 13-mm diameter) and air-dried for $30 \mathrm{~min}$, in order to avoid water contributions to the IR spectra [22,35]. From each aliquot of CCs sample, 10 microareas $\left(30 \times 30 \mu \mathrm{m}^{2}\right)$ containing densely packed cell monolayers were selected by visible microscopy, on which IR spectra were collected in the transmission mode in the medium infrared region (4000-800 $\mathrm{cm}^{-1}$ ), averaging $512 \mathrm{scans}$, with a spectral resolution of $4 \mathrm{~cm}^{-1}$, 
a zero-filling factor of 2, and a scanner velocity of $40 \mathrm{kHz}$. Background spectra were collected using the same parameters on clean zones of the $\mathrm{CaF}_{2}$ optical windows. All raw IR spectra underwent the following pre-processing procedure: the spectral contributions of water were subtracted by using an in-house optimized routine [52]; then, subtracted spectra were corrected for the contribution of atmospheric carbon dioxide and water vapor (Atmospheric compensation routine, OPUS 7.1 software, Bruker Optics, Ettlingen, Germany) and vector normalized in the entire spectral range (Normalization routine, OPUS 7.1 software). Subsequently, spectra were evaluated based on the height of the band centered at $\sim 1660 \mathrm{~cm}^{-1}$ (Amide I band of proteins), which is always the highest peak of cell spectra; average spectra with, at $1660 \mathrm{~cm}^{-1}$, absorbance values lower than 0.07 a.u. $(\sim 20 \%)$, were discarded [31]. On these pre-processed spectra, for each patient, the average absorbance spectrum and its corresponding \pm standard deviation spectra were calculated. After the calculation of second derivates (Savitzky-Golay filter, 13 points of smoothing), these spectra were curve-fitted in the $1300-900 \mathrm{~cm}^{-1}$ region, representative of nucleic acids. The selected spectral region was fitted with Gaussian band components upon straight baseline correction and vector normalization (GRAMS/AI 7.02, Galactic Industries, Inc., Salem, $\mathrm{NH}, \mathrm{USA}$ ). The underlying bands were precisely identified by second derivative results, and their center values (expressed as wavenumbers), together with the corresponding vibrational mode and biochemical assignment, are reported in Table 3.

Table 3. Center position (wavenumbers), vibrational mode, and biochemical assignment of the underlying bands as identified by curve fitting analysis of average absorbance spectra of the experimental groups in the $1300-900 \mathrm{~cm}^{-1}$ spectral range.

\begin{tabular}{ccc}
\hline Wavenumber & Vibrational Mode and Biochemical Assignment & References \\
\hline 1240 & $\begin{array}{r}\text { Asymmetric stretching vibrations of phosphate } \\
\text { moieties of A-form DNA }\end{array}$ & {$[32,37,38,53]$} \\
$\sim 1220$ & $\begin{array}{r}\text { Asymmetric stretching vibrations of phosphate } \\
\text { moieties of B-form DNA }\end{array}$ & {$[32,37,38,53]$} \\
$\sim 1087$ & $\begin{array}{r}\text { Symmetric stretching vibrations of phosphate } \\
\text { moieties in nucleic acids }\end{array}$ & {$[54-56]$} \\
$\sim 994$ & $\begin{array}{r}\text { C-C, C-O ring breathing of RNA ribose } \\
\text { Backbone vibrations of nucleic acids, mainly } \\
\text { double-strand DNA }\end{array}$ & {$[31,32,54,57]$} \\
$\sim 970$ & Left-handed helix DNA vibrations (Z-DNA) & {$[32,35,58]$} \\
$\sim 924$ & &
\end{tabular}

The integrated areas of selected underlying bands were calculated and used to obtain the following band area ratios: 1240/1220 (representing the relation between A-form and B-form DNA); 994/1087 (representing the RNA amount with respect to nucleic acids); 970/1087 (representing the double-strand DNA amount respect to nucleic acids), and 924/970 (representing the left-handed Z-DNA component of double-stranded DNA).

\section{Conclusions}

The identification of informative biomarkers is the key to understanding pathophysiological processes and represents the next crucial challenge for the development of new therapeutic strategies. The results here presented clearly evidenced how different COS protocols modulate the expression of key genes for cumulus cells' function, with different effects according to the ovarian reserve of patients. Moreover, the COS protocols demonstrated that it determines a different conformation and methylation state of cumulus cells' DNA, which resulted in being related to the expression of miRNAs and their target genes analyzed in this study. In particular, the results here presented showed that the treatment with $\mathrm{rFSH}$ is the most appropriate in patients with normal ovarian reserves, while the treatment with hMG appears to be the most suitable in patients with low ovarian reserves. These favorable effects are related to the positive control of the expression of genes involved in follicular cells' proliferation, vasculogenesis, angiogenesis, genomic integrity, and oocyte quality. 
Based on this knowledge, we firmly believe that a better understanding of the role of miRNAs and their modulation by hormonal treatment can be an important step in improving female reproductive health.

Author Contributions: Conceptualization, O.C. and M.C.; methodology, V.N., G.R., G.G., E.G., A.R.P. and F.A.C.; validation, G.R., G.G. and V.N.; formal analysis, V.N. and G.R.; data curation, G.R., N.M., M.C. and O.C.; writing-original draft preparation, G.R. and V.N; writing-review and editing, G.R., V.N., G.G., N.M. and O.C.; visualization, A.C.; supervision N.M., M.C. and O.C.; project administration, N.M., M.C. and O.C.; funding acquisition, O.C. All authors have read and agreed to the published version of the manuscript.

Funding: This research was funded by Fondo di Ateneo, Università Politecnica delle Marche 2019 to OC.

Institutional Review Board Statement: The study was conducted according to the guidelines of the Declaration of Helsinki, and approved by the Ethics Committee of Ospedali Riuniti Marche (protocol code 2020241).

Informed Consent Statement: Informed consent was obtained from all subjects involved in the study.

Data Availability Statement: Data are contained within the article.

Conflicts of Interest: The authors declare no conflict of interest.

\section{References}

1. Kidder, G.M.; Vanderhyden, B.C. Bidirectional communication between oocytes and follicle cells: Ensuring oocyte developmental competence. Can. J. Physiol. Pharmacol. 2010, 88, 399-413. [CrossRef]

2. Uyar, A.; Torrealday, S.; Seli, E. Cumulus and granulosa cell markers of oocyte and embryo quality. Fertil. Steril. 2013, 99, 979-997. [CrossRef] [PubMed]

3. Zhou, J.; Peng, X.; Mei, S. Autophagy in Ovarian Follicular Development and Atresia. Int. J. Biol. Sci. 2019, 15, 726-737. [CrossRef] [PubMed]

4. Assou, S.; Haouzi, D.; Dechaud, H.; Gala, A.; Ferrières, A.; Hamamah, S. Comparative Gene Expression Profiling in Human Cumulus Cells according to Ovarian Gonadotropin Treatments. Biomed Res. Int. 2013, 2013, 354582. [CrossRef] [PubMed]

5. Ying, S.-Y.; Chang, D.C.; Lin, S.-L. The MicroRNA (miRNA): Overview of the RNA Genes that Modulate Gene Function. Mol. Biotechnol. 2008, 38, 257-268. [CrossRef]

6. Imbar, T.; Eisenberg, I. Regulatory role of microRNAs in ovarian function. Fertil. Steril. 2014, 101, 1524-1530. [CrossRef]

7. Tu, J.; Cheung, A.H.-H.; Chan, C.L.-K.; Chan, W.-Y. The Role of microRNAs in Ovarian Granulosa Cells in Health and Disease. Front. Endocrinol. 2019, 10, 174. [CrossRef]

8. Pourteymour Fard Tabrizi, Z.; Miraj, S.; Tahmasebian, S.; Ghasemi, S. Plasma Levels of miR-27a, miR-130b, and miR-301a in Polycystic Ovary Syndrome. Int. J. Mol. Cell. Med. 2020, 9, 198-206. [CrossRef]

9. Jiang, L.; Huang, H.; Qian, Y.; Li, Y.; Chen, X.; Di, N.; Yang, D. miR-130b regulates gap junctional intercellular communication through connexin 43 in granulosa cells from patients with polycystic ovary syndrome. Mol. Hum. Reprod. 2020, 26, 576-584. [CrossRef]

10. Sinha, P.B.; Tesfaye, D.; Rings, F.; Hossien, M.; Hoelker, M.; Held, E.; Neuhoff, C.; Tholen, E.; Schellander, K.; Salilew-Wondim, D. MicroRNA-130b is involved in bovine granulosa and cumulus cells function, oocyte maturation and blastocyst formation. $J$. Ovarian Res. 2017, 10, 37. [CrossRef]

11. Zhou, J.; Liu, J.; Pan, Z.; Du, X.; Li, X.; Ma, B.; Yao, W.; Li, Q.; Liu, H. The let-7g microRNA promotes follicular granulosa cell apoptosis by targeting transforming growth factor- $\beta$ type 1 receptor. Mol. Cell. Endocrinol. 2015, 409, 103-112. [CrossRef]

12. Zhang, J.-Q.; Gao, B.-W.; Guo, H.-X.; Ren, Q.-L.; Wang, X.-W.; Chen, J.-F.; Wang, J.; Zhang, Z.-J.; Ma, Q.; Xing, B.-S. miR-181a promotes porcine granulosa cell apoptosis by targeting TGFBR1 via the activin signaling pathway. Mol. Cell. Endocrinol. 2020, 499, 110603. [CrossRef] [PubMed]

13. Krause, C.J.; Popp, O.; Thirunarayanan, N.; Dittmar, G.; Lipp, M.; Müller, G. MicroRNA-34a promotes genomic instability by a broad suppression of genome maintenance mechanisms downstream of the oncogene KSHV-vGPCR. Oncotarget 2016, 7 , 10414-10432. [CrossRef] [PubMed]

14. Tu, F.; Pan, Z.X.; Yao, Y.; Liu, H.L.; Liu, S.R.; Xie, Z.; Li, Q.F. miR-34a targets the inhibin beta B gene, promoting granulosa cell apoptosis in the porcine ovary. Genet. Mol. Res. 2014, 13, 2504-2512. [CrossRef] [PubMed]

15. Broekmans, F.J.; Kwee, J.; Hendriks, D.J.; Mol, B.W.; Lambalk, C.B. A systematic review of tests predicting ovarian reserve and IVF outcome. Hum. Reprod. Update 2006, 12, 685-718. [CrossRef] [PubMed] 
16. Broer, S.L.; Dólleman, M.; van Disseldorp, J.; Broeze, K.A.; Opmeer, B.C.; Bossuyt, P.M.M.; Eijkemans, M.J.C.; Mol, B.W.; Broekmans, F.J.M.; Broer, S.L.; et al. Prediction of an excessive response in in vitro fertilization from patient characteristics and ovarian reserve tests and comparison in subgroups: An individual patient data meta-analysis. Fertil. Steril. 2013, 100, 420-429. [CrossRef]

17. Ferraretti, A.P.; La Marca, A.; Fauser, B.C.J.M.; Tarlatzis, B.; Nargund, G.; Gianaroli, L. ESHRE consensus on the definition of "poor response" to ovarian stimulation for in vitro fertilization: The Bologna criteria. Hum. Reprod. 2011, 26, 1616-1624. [CrossRef]

18. La Marca, A.; Grisendi, V.; Griesinger, G. How Much Does AMH Really Vary in Normal Women? Int. J. Endocrinol. 2013, 2013, 959487. [CrossRef]

19. Bosch, E.; Broer, S.; Griesinger, G.; Grynberg, M.; Humaidan, P.; Kolibianakis, E.; Kunicki, M.; La Marca, A.; Lainas, G.; Le Clef, N.; et al. ESHRE guideline: Ovarian stimulation for IVF/ICSI ${ }^{\dagger}$. Hum. Reprod. Open 2020. [CrossRef]

20. Massagué, J. TGF- $\beta$ Signal Transduction. Annu. Rev. Biochem. 1998, 67, 753-791. [CrossRef]

21. Naji, M.; Aleyasin, A.; Nekoonam, S.; Arefian, E.; Mahdian, R.; Amidi, F. Differential Expression of miR-93 and miR-21 in Granulosa Cells and Follicular Fluid of Polycystic Ovary Syndrome Associating with Different Phenotypes. Sci. Rep. 2017, 7, 14671. [CrossRef] [PubMed]

22. Gioacchini, G.; Notarstefano, V.; Sereni, E.; Zacà, C.; Coticchio, G.; Giorgini, E.; Vaccari, L.; Carnevali, O.; Borini, A. Does the molecular and metabolic profile of human granulosa cells correlate with oocyte fate? New insights by Fourier transform infrared microspectroscopy analysis. Mol. Hum. Reprod. 2018, 24, 521-532. [CrossRef] [PubMed]

23. Chang, H.; Brown, C.W.; Matzuk, M.M. Genetic Analysis of the Mammalian Transforming Growth Factor- $\beta$ Superfamily. Endocr. Rev. 2002, 23, 787-823. [CrossRef]

24. Russell, D.; Salustri, A. Extracellular Matrix of the Cumulus-Oocyte Complex. Semin. Reprod. Med. 2006, 24, 217-227. [CrossRef] [PubMed]

25. Tian, X.; Pascal, G.; Monget, P. Evolution and functional divergence of NLRP genes in mammalian reproductive systems. BMC Evol. Biol. 2009, 9, 202. [CrossRef] [PubMed]

26. Zhang, P.; Dixon, M.; Zucchelli, M.; Hambiliki, F.; Levkov, L.; Hovatta, O.; Kere, J. Expression Analysis of the NLRP Gene Family Suggests a Role in Human Preimplantation Development. PLoS ONE 2008, 3, e2755. [CrossRef] [PubMed]

27. Kuchmiy, A.A.; D’Hont, J.; Hochepied, T.; Lamkanfi, M. NLRP2 controls age-associated maternal fertility. J. Exp. Med. 2016, 213, 2851-2860. [CrossRef]

28. Peng, H.; Chang, B.; Lu, C.; Su, J.; Wu, Y.; Lv, P.; Wang, Y.; Liu, J.; Zhang, B.; Quan, F.; et al. Nlrp2, a Maternal Effect Gene Required for Early Embryonic Development in the Mouse. PLoS ONE 2012, 7, e30344. [CrossRef]

29. Matthäus, C.; Bird, B.; Miljković, M.; Chernenko, T.; Romeo, M.; Diem, M. Chapter 10 Infrared and Raman Microscopy in Cell Biology. Methods Cell Biol. 2008, 89, 275-308. [CrossRef]

30. Baker, M.J.; Trevisan, J.; Bassan, P.; Bhargava, R.; Butler, H.J.; Dorling, K.M.; Fielden, P.R.; Fogarty, S.W.; Fullwood, N.J.; Heys, K.A.; et al. Using Fourier transform IR spectroscopy to analyze biological materials. Nat. Protoc. 2014, 9, 1771-1791. [CrossRef]

31. Giorgini, E.; Sabbatini, S.; Rocchetti, R.; Notarstefano, V.; Rubini, C.; Conti, C.; Orilisi, G.; Mitri, E.; Bedolla, D.E.; Vaccari, L. In vitro FTIR microspectroscopy analysis of primary oral squamous carcinoma cells treated with cisplatin and 5-fluorouracil: A new spectroscopic approach for studying the drug-cell interaction. Analyst 2018, 143, 3317-3326. [CrossRef] [PubMed]

32. Notarstefano, V.; Sabbatini, S.; Pro, C.; Belloni, A.; Orilisi, G.; Rubini, C.; Byrne, H.J.; Vaccari, L.; Giorgini, E. Exploiting fourier transform infrared and Raman microspectroscopies on cancer stem cells from oral squamous cells carcinoma: New evidence of acquired cisplatin chemoresistance. Analyst 2020, 145, 8038-8049. [CrossRef] [PubMed]

33. Notarstefano, V.; Belloni, A.; Sabbatini, S.; Pro, C.; Orilisi, G.; Monterubbianesi, R.; Tosco, V.; Byrne, H.J.; Vaccari, L.; Giorgini, E. Cytotoxic Effects of 5-Azacytidine on Primary Tumour Cells and Cancer Stem Cells from Oral Squamous Cell Carcinoma: An In Vitro FTIRM Analysis. Cells 2021, 10, 2127. [CrossRef]

34. Gioacchini, G.; Giorgini, E.; Vaccari, L.; Ferraris, P.; Sabbatini, S.; Bianchi, V.; Borini, A.; Carnevali, O. A new approach to evaluate aging effects on human oocytes: Fourier transform infrared imaging spectroscopy study. Fertil. Steril. 2014, 101, 120-127. [CrossRef] [PubMed]

35. Notarstefano, V.; Gioacchini, G.; Byrne, H.J.H.J.; Zacà, C.; Sereni, E.; Vaccari, L.; Borini, A.; Carnevali, O.; Giorgini, E. Vibrational characterization of granulosa cells from patients affected by unilateral ovarian endometriosis: New insights from infrared and Raman microspectroscopy. Spectrochim. Acta Part A Mol. Biomol. Spectrosc. 2019, 212, 206-214. [CrossRef]

36. Notarstefano, V.; Gioacchini, G.; Giorgini, E.; Montik, N.; Ciavattini, A.; Polidori, A.R.; Candela, F.A.; Vaccari, L.; Cignitti, M.; Carnevali, O. The Impact of Controlled Ovarian Stimulation Hormones on the Metabolic State and Endocannabinoid System of Human Cumulus Cells. Int. J. Mol. Sci. 2020, 21, 7124. [CrossRef]

37. Whelan, D.R.; Bambery, K.R.; Heraud, P.; Tobin, M.J.; Diem, M.; McNaughton, D.; Wood, B.R. Monitoring the reversible B to A-like transition of DNA in eukaryotic cells using Fourier transform infrared spectroscopy. Nucleic Acids Res. 2011, 39, 5439-5448. [CrossRef]

38. Ghosh, D.; Dey, S.K.; Saha, C. Mutation Induced Conformational Changes in Genomic DNA from Cancerous K562 Cells Influence Drug-DNA Binding Modes. PLoS ONE 2014, 9, e84880. [CrossRef]

39. Mignolet, A.; Derenne, A.; Smolina, M.; Wood, B.R.; Goormaghtigh, E. FTIR spectral signature of anticancer drugs. Can drug mode of action be identified? Biochim. Biophys. Acta Proteins Proteom. 2016, 1864, 85-101. [CrossRef] 
40. Herbert, A.; Rich, A. The biology of left-handed Z-DNA. J. Biol. Chem. 1996, 271, 11595-11598. [CrossRef]

41. Temiz, N.A.; Donohue, D.E.; Bacolla, A.; Luke, B.T.; Collins, J.R. The Role of Methylation in the Intrinsic Dynamics of B- and Z-DNA. PLoS ONE 2012, 7, e035558. [CrossRef] [PubMed]

42. Alviggi, C.; Humaidan, P.; Ezcurra, D. Hormonal, functional and genetic biomarkers in controlled ovarian stimulation: Tools for matching patients and protocols. Reprod. Biol. Endocrinol. 2012, 10, 9. [CrossRef]

43. Zhang, Q.; Sun, H.; Jiang, Y.; Ding, L.; Wu, S.; Fang, T.; Yan, G.; Hu, Y. MicroRNA-181a Suppresses Mouse Granulosa Cell Proliferation by Targeting Activin Receptor IIA. PLoS ONE 2013, 8, e59667. [CrossRef] [PubMed]

44. Duncan, W. The human corpus luteum: Remodelling during luteolysis and maternal recognition of pregnancy. Rev. Reprod. 2000, 5, 12-17. [CrossRef]

45. Rothenburg, S.; Koch-Nolte, F.; Haag, F. DNA methylation and Z-DNA formation as mediators of quantitative differences in the expression of alleles. Immunol. Rev. 2001, 184, 286-298. [CrossRef]

46. Dovbeshko, G.I.; Chegel, V.I.; Gridina, N.Y.; Repnytska, O.P.; Shirshov, Y.M.; Tryndiak, V.P.; Todor, I.M.; Solyanik, G.I. Surface enhanced IR absorption of nucleic acids from tumor cells: FTIR reflectance study. Biopolymers 2002, 67, 470-486. [CrossRef] [PubMed]

47. Shi, R.; Sun, Y.-H.; Zhang, X.-H.; Chiang, V.L. Poly(T) Adaptor RT-PCR. In Next-Generation MicroRNA Expression Profiling Technology; Fan, J.-B., Ed.; Humana Press: Totowa, NJ, USA, 2012; pp. 53-66.

48. Bustin, S.A.; Benes, V.; Garson, J.A.; Hellemans, J.; Huggett, J.; Kubista, M.; Mueller, R.; Nolan, T.; Pfaffl, M.W.; Shipley, G.L.; et al. The MIQE Guidelines: Minimum Information for Publication of Quantitative Real-Time PCR Experiments. Clin. Chem. 2009, 55, 611-622. [CrossRef]

49. Pfaffl, M.W. A new mathematical model for relative quantification in real-time RT-PCR. Nucleic Acids Res. 2001, 29, e45. [CrossRef]

50. Vandesompele, J.; De Preter, K.; Pattyn, F.; Poppe, B.; Van Roy, N.; De Paepe, A.; Speleman, F. Accurate normalization of real-time quantitative RT-PCR data by geometric averaging of multiple internal control genes. Genome Biol. 2002, 3, research0034.1. [CrossRef] [PubMed]

51. Karagkouni, D.; Paraskevopoulou, M.D.; Chatzopoulos, S.; Vlachos, I.S.; Tastsoglou, S.; Kanellos, I.; Papadimitriou, D.; Kavakiotis, I.; Maniou, S.; Skoufos, G.; et al. DIANA-TarBase v8: A decade-long collection of experimentally supported miRNA-gene interactions. Nucleic Acids Res. 2018, 46, D239-D245. [CrossRef]

52. Vaccari, L.; Birarda, G.; Businaro, L.; Pacor, S.; Grenci, G. Infrared Microspectroscopy of Live Cells in Microfluidic Devices (MD-IRMS): Toward a Powerful Label-Free Cell-Based Assay. Anal. Chem. 2012, 84, 4768-4775. [CrossRef]

53. Weniger, M.; Honselmann, K.C.; Liss, A.S. The Extracellular Matrix and Pancreatic Cancer: A Complex Relationship. Cancers 2018, 10, 316. [CrossRef]

54. Zucchiatti, P.; Mitri, E.; Kenig, S.; Billè, F.; Kourousias, G.; Bedolla, D.E.; Vaccari, L. Contribution of Ribonucleic Acid (RNA) to the Fourier Transform Infrared (FTIR) Spectrum of Eukaryotic Cells. Anal. Chem. 2016, 88, 12090-12098. [CrossRef] [PubMed]

55. Notarstefano, V.; Sabbatini, S.; Conti, C.; Pisani, M.; Astolfi, P.; Pro, C.; Rubini, C.; Vaccari, L.; Giorgini, E. Investigation of human pancreatic cancer tissues by Fourier Transform Infrared Hyperspectral Imaging. J. Biophotonics 2020, 13, e201960071. [CrossRef]

56. Notarstefano, V.; Sabbatini, S.; Sabbatini, M.; Arrais, A.; Belloni, A.; Pro, C.; Vaccari, L.; Osella, D.; Giorgini, E. Hyperspectral characterization of the MSTO-211H cell spheroid model: A FPA-FTIR imaging approach. Clin. Spectrosc. 2021, $3,100011$. [CrossRef]

57. Talari, A.C.S.; Martinez, M.A.G.; Movasaghi, Z.; Rehman, S.; Rehman, I.U. Advances in Fourier transform infrared (FTIR) spectroscopy of biological tissues. Appl. Spectrosc. Rev. 2017, 52, 456-506. [CrossRef]

58. Banyay, M.; Sarkar, M.; Gräslund, A. A library of IR bands of nucleic acids in solution. Biophys. Chem. 2003, 104, 477-488. [CrossRef]

59. Gioacchini, G.; Giorgini, E.; Olivotto, I.; Maradonna, F.; Merrifield, D.L.; Carnevali, O. The Influence of Probiotics on Zebrafish Danio Rerio Innate Immunity and Hepatic Stress. Zebrafish 2014, 11, 98-106. [CrossRef] 